\title{
Diagnóstico do mercado varejista de flores de Santa Maria, RS ${ }^{(1)}$
}

\author{
JANINE FARIAS MENEGAES(2), FERNANDA ALICE ANTONELLO LONDERO BACKES(2), \\ ROGÉRIO ANTÔNIO BELLÉ(2) e ROGÉRIO LUIZ BACKES(2)
}

\begin{abstract}
RESUMO
O presente trabalho teve como objetivo diagnosticar o mercado varejista de flores e plantas ornamentais do município de Santa Maria, RS, Brasil, por meio de pesquisa in loco, entre os meses de janeiro e junho de 2013, a partir de questionários e entrevistas com os responsáveis pelos estabelecimentos comerciais, e da aplicação de uma escala visual e fitossanitária aos demais estabelecimentos que comercializam flores e plantas ornamentais, tais como lojas agropecuárias, feiras de produtos hortigranjeiros, supermercados e prestadores de serviços fúnebres - cemitérios e funerárias. O diagnóstico buscou conhecer as etapas da dinâmica do mercado de flores do município, até o consumidor final. Além disso, visou segmentar os tipos de floriculturas distinguindo-as conforme o enfoque comercial, em floriculturas de arranjos florais, buquês e flores envasadas, floriculturas produtoras e floriculturas paisagistas. Com base no diagnóstico, concluiu-se que o varejo de flores e plantas ornamentais santa-mariense segue a tendência nacional de lojas de arranjos e buquês florais, com ascensão das empresas voltadas para o paisagismo e a jardinagem. Em relação às plantas mais comercializadas destacam-se a rosa como flor de corte, a begônia como flor envasada, a samambaia para folhagem de arranjo, os cactos para plantas envasadas, a ráfis para planta de jardim e o amor-perfeito como caixaria.
\end{abstract}

Palavras-chave: floricultura, mercado de flores e plantas ornamentais, questionário, escala de turgidez e de sanidade.

\begin{abstract}
Diagnosis of the retail flower market of Santa Maria, RS

The present study aimed to diagnose the flowers retail market and ornamental plants in Santa Maria, RS, Brazil, by means of a research in loco, from January to June of 2013, based on questionnaires and interviews applied to the managers of the establishment, as well as of an application of a visual and phytosanitary scale to other establishments that sell flowers and ornamental plants, such as agricultural shops, fairs of horticultural products, supermarkets and providers of funeral services - cemeteries and funeral homes. The diagnosis aims to know the steps of the dynamics observed from the market of flowers until the final consumer, and to segment the types of floricultures, distinguishing them according to the commercial focus - floricultures of arrangements and bouquets, and producing flowers and landscape floricultures. Based on the diagnosis it can be concluded that the Santa Maria retail flowers and ornamental plants follows the national trend of floral arrangements and bouquets shops, with the increase of the companies focused on landscaping and gardening. Among the most marketed plants are the rose as the best-selling cut flower, the begonia as potted flower, the fern for foliage arrangements, the cactus as potted plant, the raffia as garden plant and the pansy as the best-selling plant in boxes.
\end{abstract}

Keywords: floriculture, market flowers and ornamental plants, questionnaire, scale of turgidity and sanity.

\section{INTRODUÇÃO}

A floricultura é um ramo do agronegócio que abrange grande diversidade de produtos comerciais, como flores de corte, flores de vaso, folhagens e plantas para paisagismo, como árvores, arbustos e forrações, com qualidade estética visual e fitossanitária. E, com alta rentabilidade por área, a floricultura tende a contribuir para a permanência do homem no campo, pois o cultivo é viável em pequena propriedade, e tem como característica a mão de obra familiar (KÄMPF; DAUDT, 1999). Conforme Kämpf (2000), a floricultura é uma atividade agrícola de exploração intensiva e de cunho empresarial.

Nesse panorama estão sendo geradas inúmeras novas oportunidades de negócios e de inserção comercial competitiva, eficiente e sustentável para os polos emergentes de produção distribuídos por todo o país (JUNQUEIRA e PEETZ, 2008). O setor da floricultura no Brasil vem experimentando sucessivas taxas de crescimento da ordem de $8-10 \%$ ao ano nas quantidades e de $12-15 \%$ nos valores comercializados. Tais índices, bastante acima dos níveis médios de crescimento do PIB nacional, comprovam a alta possibilidade de crescimento sustentado da atividade no país (TOMBOLATO et al., 2010).

Os dados da cadeia brasileira de flores e plantas ornamentais são promissores, como relata Schoenmaker (2013), com média atual de consumo per capita $\mathrm{R} \$ 26,00$, área de cultivo de 13,8 mil hectares, cerca de oito mil produtores, em propriedades de 2,5 hectares em média, produzindo mais de 350 espécies e três mil variedades. Além disso, conta com mais de 60 centrais de atacado, 650 empresas atacadistas, 22 mil pontos de venda no varejo e mais de 30 feiras e exposições, de abrangência nacional.

O Complexo Agroindustrial das Flores do Brasil proposto por Claro et al. (1999) agrupa o setor por agregados, como: Agregado I, formado pelos fornecedores de insumos; Agregado II, constituído pelos produtores rurais e Agregado III, formado pelos leilões, supermercados, varejistas (floriculturas), funerárias e, finalmente, os consumidores. O foco do presente trabalho é o Agregado III proposto por

\footnotetext{
(1) Recebido em 17/06/2014 e aceito em 09/03/2015.

(2) Universidade Federal de Santa Maria (UFSM), Departamento de Fitotecnia, Santa Maria-RS, Brasil. *Autor correspondente: janine_rs@hotmail.com
} 
Claro et al. (1999). Os mesmos autores citam Almeida e Aki (1995), e consideram que a distribuição varejista de flores é realizada por meio dos seguintes canais: floriculturas estabelecimentos comerciais varejistas (55\%), decoradores (20\%), funerárias $(10 \%)$, supermercados $(8 \%)$, floras $(5 \%)$, outros (2\%). Da mesma forma, os autores citam Santana (1997) e relatam que as vendas de flores em supermercados cresceram muito rapidamente nas grandes cidades e os cash and carries estão se espalhando por todo o país.

O varejo brasileiro de flores e plantas ornamentais é constituído por um conjunto diversificado de formatos de negócios e de empreendimentos, formais e informais, de micro, pequeno, médio ou grande porte, presentes em quase todas as cidades. Trata-se, na realidade, de uma rede de grande penetração e capilaridade geográfica, que permite a organização de extensos fluxos de comércio, desde as principais zonas de produção da floricultura nacional (especialmente os estados da Região Sudeste e Sul) até os mais longínquos pontos de consumo (SEBRAE, 2010).

No setor varejista, proposto por Junqueira e Peetz (2008), observam-se grandes movimentos de alteração na participação relativa dos equipamentos e canais de distribuição no varejo. Assim, as alternativas mais modernas e dinâmicas da distribuição, capazes de inovar e fornecer diferenciais significativos não apenas de preços, mas também de comodidade, conforto e conveniência, como os supermercados e garden centers vêm conquistando rapidamente maiores segmentos deste mercado.

As floriculturas varejistas, de acordo com Claro et al. (1999), são estabelecimentos comerciais varejistas que se dedicam à venda de flores e algumas plantas ornamentais. Este setor trabalha com a criatividade para vender arranjos e buquês e tem como mercado alvo o consumidor final. Existem ainda, segundo Padula et al. (2003), os seguimentos lojas de arte floral, garden centers, supermercados e vendedores ambulantes.

Os estabelecimentos de varejo do setor complementar de produtos florais e ornamentais podem ser classificados, para Santa Maria, como os descritos a seguir: as lojas agropecuárias ou revendas agrícolas como são chamadas, proporcionam serviços diferenciados relacionados à aplicação de produtos, assistência técnica e consultoria (CASTRO, 1998; AKI, 2000), as feiras hortigranjeiras têm diversificado o oferecimento de produtos e, atualmente, dispõem de hortigranjeiros, plantas ornamentais, artesanato, quitandas, desde produtos sofisticados até mercadorias para as camadas mais populares (BONGERS, 2002). Os supermercados por sua vez, têm desempenhado papel de relevância crescente na venda de flores e plantas ornamentais, transformando-se em importante canal de distribuição, podendo contribuir para criar e consolidar o hábito de consumo em parcela significativa da população ainda não habituada a adquirir estes produtos (CLARO et al., 1999; JUNQUEIRA e PEETZ, 2008).

Entre os estabelecimentos de prestação de serviços fúnebres de floricultura, destacam-se os cemitérios e as funerárias que ocupam um grande nicho do mercado floral do país, que segundo Aki (2002), movimenta R\$ 135 milhões de reais em vendas de flores ao ano a preço de varejo. O mesmo autor, em 2010, diz que, no período de celebração de finados, cerca de $15 \%$ da população vai aos cemitérios, e que uma coroa costuma custar entre R\$ 50,00 a R\$ 500,00. Em geral, os trabalhos funerários não são mais vendidos pelas funerárias, e sim, pelos planos funerários. Desta forma, as coroas não são mais elaboradas pelas funerárias, sendo este serviço terceirizado com o atendimento das floriculturas.

Tradicionalmente, o Rio Grande do Sul destaca-se como grande consumidor de flores e plantas ornamentais. $\mathrm{Na}$ região central do estado, onde está localizado o município de Santa Maria, o mercado varejista de flores e plantas ornamentais é caracterizado por dois modos distintos quanto ao objetivo principal de comercialização - no primeiro, tem-se o foco na venda de produtos florais e ornamentais, comercializados pelas floriculturas, e o segundo é representado pelos estabelecimentos em que as flores e plantas ornamentais fazem parte de um mix de produtos ofertados, tais como, lojas agropecuárias, feiras hortigranjeiras e supermercados, e também os estabelecimentos prestadores de serviços fúnebres.

O objetivo do trabalho foi diagnosticar e analisar os diferentes setores que compreendem o mercado varejista de flores do município de Santa Maria, RS.

\section{MATERIAL E MÉTODOS}

A pesquisa foi desenvolvida no período de janeiro a junho de 2013, em Santa Maria, região central do Rio Grande do Sul. Este município tem mais de 260 mil habitantes, sendo considerada a $5^{a}$ cidade mais populosa do estado, inserida em uma região com aproximadamente um milhão de habitantes (IBGECidades@, 2010).A pesquisa constou de levantamento quantitativo dos estabelecimentos que pertencem ao setor de floricultura e plantas ornamentais, tendo sido adaptada de acordo ao Agregado III proposto por Claro et al. (1999) que contempla: floriculturas varejistas, lojas agropecuárias, feiras hortigranjeiras, supermercados, cemitérios e funerárias.

A execução da caracterização do mercado varejista de flores, plantas ornamentais e afins do município ocorreu em dois momentos. Primeiramente, com o pré-levantamento dos estabelecimentos varejistas, pelo método de pesquisa em listas telefônicas locais e via internet, visando quantificar o número de estabelecimentos em funcionamento em Santa Maria. As listas telefônicas impressas consultadas foram dos anos de 2010, 2011 e 2012.

O segundo momento da pesquisa foi definido representando as visitas às floriculturas varejistas e aos estabelecimentos que apresentam a comercialização de flores e plantas ornamentais como opção comercial secundária ou complementar, sendo lojas agropecuárias, feiras hortigranjeiras e supermercados e estabelecimentos de prestação de serviços fúnebres, como os cemitérios e as funerárias. Para a obtenção dos dados quantitativos realizouse uma entrevista com os proprietários das floriculturas varejistas com a aplicação do questionário (Figura 1), elaborado pelos autores para este trabalho, no total foram 23 estabelecimentos visitados. $\mathrm{O}$ objetivo deste questionário foi diagnosticar, através de dados e relatos, a cadeia de flores e plantas ornamentais do município, seus colaboradores e os principais entraves do setor da floricultura. 


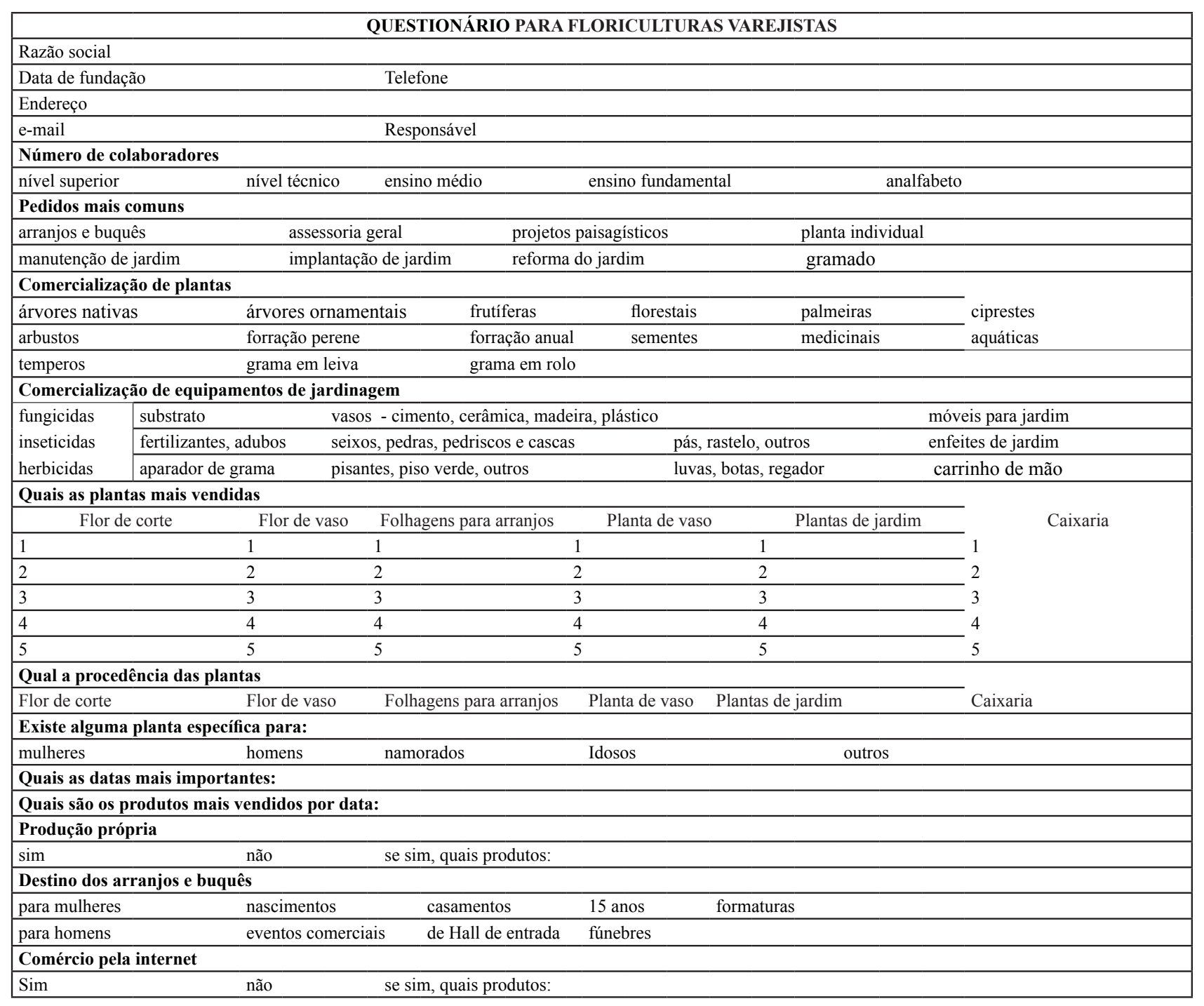

Figura 1. Questionário aplicado às floriculturas sobre o mercado de flores de Santa Maria.

Figure 1. Questionnaire applied to flower shops on the flower market of Santa Maria.

Nos estabelecimentos com comercialização secundária ou complementar de flores e plantas ornamentais, realizouse uma avaliação qualitativa das espécies comercializadas, com enquadramento visual, através da escala de turgidez e de fitossanidade (Tabela 1), elaborada pelos autores.

\section{RESULTADOS E DISCUSSÃO}

Verificou-se no pré-levantamento dos estabelecimentos de flores e plantas ornamentais no município, via internet o número de 38 floriculturas e nas listas telefônicas impressas o número de 27 floriculturas, após a conferência in loco de todos os estabelecimentos, constatou-se um total de 23 estabelecimentos comerciais em pleno funcionamento.

Durante a realização das entrevistas e aplicação do questionário às floriculturas varejistas, observou-se o interesse dos floristas em responder as questões, bem como a exposição de suas opiniões referentes ao setor em questão. Verificou-se que há a preocupação dos floristas quanto à comercialização de flores e plantas ornamentais, principalmente pelo advento da competição dos supermercados, visto que, nos últimos anos, estes estabelecimentos iniciaram a comercialização de produtos oriundos da floricultura.

Quanto à origem das flores e plantas ornamentais para o mercado de Santa Maria verificou-se que são oriundas principalmente dos Estados de São Paulo (21 estabelecimentos entrevistados), Rio Grande do Sul (19 estabelecimentos entrevistados) e Santa Catarina (11 estabelecimentos entrevistados). Segundo relato dos floristas, os produtos das floriculturas vindos de SP estão vinculados à Cooperativa Veiling Holambra, sendo as flores de corte e de vaso, os principais produtos adquiridos, especialmente pelo menor preço, confiança no volume disponibilizado e boa qualidade visual e fitossanitária.

Em relação às datas comemorativas que impulsionam o setor de floricultura em Santa Maria, RS, todos os entrevistados destacaram o Dia das Mães como o mais importante, sendo comercializado cerca de $40 \%$ a mais de 
Tabela 1. Escala de turgidez e de sanidade.

Table 1. Scale of turgidity and sanity.

\begin{tabular}{|c|l|}
\hline NOTA & ESCALA DE TURGIDEZ E FITOSSANIDADE \\
\hline 1 & $\begin{array}{l}\text { Produto com turgidez aparente dos tecidos (folhas e flores), ausência de danos de pragas, doenças, mecânicos, } \\
\text { deformações, necroses e amarelecimento dos tecidos. }\end{array}$ \\
\hline 2 & $\begin{array}{l}\text { Produto com turgidez aparente dos tecidos (folhas e flores), ausência de danos de pragas, doenças, mecânicos, } \\
\text { deformações, necroses e presença de amarelecimento dos tecidos. }\end{array}$ \\
\hline 3 & $\begin{array}{l}\text { Produto com turgidez aparente dos tecidos (folhas e flores), presença de danos de pragas, doenças, mecânicos, } \\
\text { deformações, necroses e ausência de amarelecimento dos tecidos. }\end{array}$ \\
\hline 4 & $\begin{array}{l}\text { Produto com turgidez aparente dos tecidos (folhas e flores), presença de danos de pragas, doenças, mecânicos, } \\
\text { deformações, necroses e amarelecimento dos tecidos. }\end{array}$ \\
\hline 5 & $\begin{array}{l}\text { Produto com falta de turgidez aparente dos tecidos (folhas e flores), ausência de danos de pragas, doenças, } \\
\text { mecânicos, deformações, necroses e amarelecimento dos tecidos. }\end{array}$ \\
\hline 6 & $\begin{array}{l}\text { Produto com falta de turgidez aparente dos tecidos (folhas e flores), ausência de danos de pragas, doenças, } \\
\text { mecânicos, deformações, necroses e presença de amarelecimento dos tecidos. }\end{array}$ \\
\hline 7 & $\begin{array}{l}\text { Produto com falta de turgidez aparente dos tecidos (folhas e flores), presença de danos de pragas, doenças, } \\
\text { mecânicos, deformações, necroses e ausência de amarelecimento dos tecidos. }\end{array}$ \\
\hline 9 & $\begin{array}{l}\text { Produto com falta de turgidez aparente dos tecidos (folhas e flores), presença de danos de pragas, doenças, } \\
\text { mecânicos, deformações, necroses e amarelecimento dos tecidos. }\end{array}$ \\
\hline Produto em ponto de murcha permanente.
\end{tabular}

Tabela 2. Principais espécies ornamentais comercializadas por categoria de produto. Santa Maria, 2013.

Table 2. Main ornamental species marketed by product category. Santa Maria, in 2013.

\begin{tabular}{|c|c|c|c|c|c|}
\hline Flor de corte & Flor envasada & $\begin{array}{c}\text { Folhagens para } \\
\text { arranjos }\end{array}$ & Planta envasada & $\begin{array}{c}\text { Plantas de } \\
\text { jardim }\end{array}$ & Caixaria \\
\hline Rosa & Begônia & Samambaia & Cactus & Rafis & Amor-perfeito \\
\hline Gérbera & Crisântemo & Aspargo & Temperos & Dracena & Sáletes \\
\hline Alstroemeria & Ciclâmen & Moreia & Lírio da paz & Fênix \\
\hline Gipsofila & Antúrio & Murta & Pimentas ornamentais & Buxus & Pervinca \\
\hline Solidaster & Kalanchoe & Cheflera & Jiboia & Cróton & Beijo \\
\hline
\end{tabular}

produtos que a média mensal. Datas como Finados, Dia dos Namorados, Dia dos Pais, Dia da Secretária, Dia da Avó e datas de fim de ano foram lembradas como importantes para o setor. Para o mercado de flores e plantas ornamentais do município, as datas de maior potencial comercial são o Dia Internacional da Mulher, o Dia dos Pais, Natal, Ano Novo e datas religiosas locais (Nossa Senhora Medianeira e Nossa Senhora Aparecida).

As floriculturas se caracterizam como estabelecimentos comerciais de varejo, comercializando flores envasadas, com ou sem enfeites decorativos, flores de corte (em maços com e sem enfeites decorativos, arranjos com e sem presentes (acompanham as flores em arranjos, variando desde bombons, cartões, vinhos, canecas, perfumes, bichinhos de pelúcia, a cestas de café da manhã, entre outros), buquês florais e coroas fúnebres); plantas ornamentais (árvores, palmeiras, coníferas, arbustos, trepadeiras, forrações perenes e anuais, gramados, mudas de plantas medicinais, temperos e aromáticas), sementes de ornamentais, com ou sem prestação de serviços de paisagismo (elaboração e implantação de projetos) e jardinagem (manutenção e reformas), implementos e equipamentos para jardinagem, substratos e artigos de ornamentação em geral.

Para o melhor entendimento do segmento de mercado de flores e plantas ornamentais em Santa Maria, estas empresas foram segmentadas em grupos:

Floriculturas de Arranjos, Buquês e Envasadas - FAB: são empresas que comercializam flores e plantas envasadas; 
flores e folhagens de corte na forma de arranjos (com e sem presentes), buquês florais, e coroas fúnebres. Este grupo totalizou 14 estabelecimentos;

Floriculturas Paisagistas - FPA: são empresas que comercializam flores e plantas envasadas e todos os tipos de plantas ornamentais, elaboram e implantam projetos paisagísticos, comercializam implementos e equipamentos para jardinagem, substratos e outros acabamentos, bem como prestam serviços de jardinagem (manutenção). Este grupo totalizou sete empresas;

Floriculturas Produtoras - FPR: são empresas que comercializam flores de corte na forma de arranjos e buquês florais, flores e plantas envasadas e todos os tipos de plantas ornamentais, implementos e equipamentos para jardinagem, substratos e outros acabamentos, produzindo também algumas espécies de plantas ornamentais que comercializam. Dois estabelecimentos integram este grupo.

Esta divisão possibilitou conhecer cada ramo do setor comercialização de produtos de flores e plantas ornamentais e afins, podendo até mesmo auxiliar os produtores e donos de floriculturas na especialização tanto na oferta do mix de produtos florais e ornamentais como na manutenção da carteira de clientes.

As vendas on line realizadas pelas empresas de flores e plantas ornamentais são realizadas por $12(\mathrm{FAB}$, 10; FPA, 1 e FPR, 1) das 23 existentes, sendo que estes estabelecimentos têm contrato comercial com apenas dois endereços eletrônicos de abrangência nacional, os quais são responsáveis por toda a transação eletrônica de pagamento e forma de entrega do produto. O objeto destas vendas on line são geralmente arranjos e buquês, com ou sem presentes, e coroas fúnebres, e os clientes são majoritariamente de outros municípios.

Quanto aos serviços ofertados pelas floriculturas varejistas em Santa Maria, constatou que a grande maioria oferta o tradicional serviço de arranjos e buquês, totalizando 18 das 23 floriculturas existentes no município, sendo 14 destes estabelecimentos especializados neste nicho de mercado. Já as floriculturas paisagistas, estão localizadas nos bairros fora do eixo principal de comércio, por se caracterizarem como estabelecimentos maiores, em função do espaço físico e do volume de plantas estocadas. As floriculturas FPA têm como principais produtos de comercialização aqueles voltados ao paisagismo desde a elaboração do projeto, execução e em alguns casos, a manutenção mensal dos jardins.

Entre as plantas ornamentais mais comercializadas em Santa Maria destacam-se as forrações perenes e anuais citadas por 14 empresas entrevistadas, seguidas por 13 empresas que comercializam palmeiras e arbóreas ornamentais e 12 empresas que comercializam arbustos. As mudas de espécies frutíferas são destaque em 11 empresas, e por sua vez, as gramas em leiva, temperos e aromáticas, ciprestes e mudas arbóreas nativas, em dez empresas; grama em rolo em oito estabelecimentos; espécies aquáticas e mudas florestais em sete empresas, e apenas cinco estabelecimentos comercializam sementes de espécies ornamentais.

Salienta-se que, por categoria de produtos (Tabela 2), as plantas mais comercializadas como flores de corte são a rosa, a gérbera e a alstroemeria, sendo a rosa destinada para $80 \%$ dos arranjos e buquês florais, enquanto a gipsofila e o solidaster destacam-se como complementos de arranjos. $\mathrm{Na}$ categoria flores envasadas destacam-se begônias, ciclâmens, antúrios e kalanchoes, enquanto os crisântemos envasados têm como principal destino os cemitérios. Verificou-se que as plantas envasadas apresentam uma variação de preferências quanto à finalidade, sendo destaque os cactos, os temperos, o lírio da paz e as pimentas ornamentais. $\mathrm{Na}$ categoria de folhagens para arranjos destacam-se a samambaia/avencão, aspargo, moreia, murta e cheflera. As plantas de jardim e caixaria apresentam sazonalidade anual, variando com as estações, sendo muito comercializadas para uso em paisagismo.

Verificou-se que as floriculturas paisagistas e produtoras, totalizando nove estabelecimentos entrevistados, ofertam materiais e equipamentos tanto para jardinagem (pás, luvas, regadores, outros) como para complementação do paisagismo (aparadores de grama, pisantes, vasos, móveis e enfeites para jardim), além de produtos fitossanitários, fertilizantes e substratos.

Nas 23 floriculturas entrevistadas, em Santa Maria, foram contabilizadas 3,83 pessoas/floricultura, totalizando 88 pessoas envolvidas neste setor, sendo $56,8 \%$ do sexo feminino. Este número é menor que o citado por Aki (2010), de cinco pessoas/floricultura incluindo proprietários e funcionários. Quanto ao grau de escolaridade, foi verificado que $58 \%$ dos envolvidos possuem ensino médio, $15 \%$ o ensino fundamental, $14 \%$ o ensino técnico e $13 \%$ tem ensino superior. Em relação aos envolvidos que concluíram o ensino superior observou-se que são poucos aqueles especializados na área, tendo sido encontrados apenas três com título de Engenheiros Agrônomos.

$\mathrm{O}$ enquadramento das flores e plantas ornamentais na escala (Tabela 1) teve o objetivo de avaliar a turgidez e a fitossanidade dos produtos comercializados nos estabelecimentos em Santa Maria, RS. Algumas vezes, estes não se preocupam com a qualidade dos produtos da floricultura e, em datas especiais como, Dia das Mães, Dia dos Pais, Dia dos Namorados e Finados comercializam os produtos com qualidade inferior a exigida pelo mercado de flores e plantas ornamentais.

Por sua vez, as lojas agropecuárias e afins, totalizando quatro entrevistadas, são estabelecimentos que visam atender o produtor rural, com produtos para fins e usos na agricultura (fertilizantes, agrotóxicos, mudas de flores e hortaliças) e na pecuária (rações, remédios, outros). Há uma preocupação destes estabelecimentos com a qualidade das plantas, pois trabalham diretamente com produtores de diversas categorias agrícolas, observando-se bons índices quanto à turgidez e a fitossanidade, tendo sido verificadas notas de 1 a 3 na escala.

As quatro feiras hortigranjeiras visitadas, visam movimentar a economia local dos bairros, trazendo alternativas de consumo de produtos alimentícios e não alimentícios frescos, oriundos da região e adjacências e, geralmente, ocorrem uma vez por semana. A comercialização de flores é voltada, principalmente, para as datas específicas como Dia das Mães, Dia dos Namorados, Dia dos Pais e Finados. A produção local de flores gera 
em torno de $20 \%$ do volume comercializado, sendo $80 \%$ proveniente da CEASA de Porto Alegre. Os produtos analisados nas feiras apresentam notas da escala de 2 e 3 .

Os supermercados, grandes estabelecimentos estruturados em departamentos que oferecem um estoque relativamente amplo e completo de mantimentos, são operados basicamente no sistema de autosserviço. Nestes, a apresentação dos produtos florais se dá de duas formas, com ou sem embalagens especiais, tais como: papéis coloridos, celofanes, caixas de papel e fitas coloridas, que entanto, afetam o valor final do produto. Neste trabalho avaliaramse sete redes supermercadistas no município. As notas para os produtos analisados neste tipo de comércio variaram de 1 a 4 . Verificou-se que nos dias em que os produtos chegam às gôndolas a nota pode ser atribuída como 1, porém com o passar dos dias os produtos perdem qualidade e as notas oscilam de 2 a 4 , provavelmente por não haver pessoas treinadas ou especializadas no manejo destas plantas.

Andrade (2013), diz também que o ingresso do varejo supermercadista no segmento repercutiu em ganho na floricultura nacional. O número de pontos de venda aumentou e, consequentemente, maior número de pessoas passou a ter acesso ao produto. Isto indica um benefício para a base da cadeia de flores e plantas ornamentais do país, pelo potencial de aumento da demanda. Provavelmente, o destino das flores e plantas envasadas adquiridas nos supermercados seja prioritariamente o uso doméstico. No entanto, a qualidade destes produtos é visualmente inferior quando comparada à das floriculturas, assim como o valor dos produtos, em geral, é menor. Este comportamento pode se transformar em hábito, garantindo um consumo constante destes produtos, como ocorre, por exemplo, com as frutas e hortaliças. Contudo, há uma reclamação generalizada por parte dos floristas quanto à permissão da comercialização de produtos deste gênero, pois segundo eles houve uma representativa redução nas vendas flores e plantas envasadas, sobretudo nas datas comemorativas (destaque para Finados), pois para as floriculturas varejistas torna-se difícil competir com as redes supermercadistas, principalmente no que se refere ao preço ofertado ao consumidor.

Os serviços fúnebres no município de Santa Maria são representados pelos cemitérios e pelas funerárias. A comercialização de flores nos cemitérios ocorre de duas formas, a primeira, em datas específicas como, por exemplo, Finados (neste caso a mais importante deste item) em que as vendas são realizadas por vendedores ambulantes, que nem sempre obtêm licenças para comercializar flores na entrada dos cemitérios na data e nos dias que a antecedem. Em seguida, outras datas importantes como Dia das Mães, Dia dos Pais e festividades de final de ano marcam a comercialização de flores e plantas ornamentais. Nos cemitérios ocorre também a comercialização contínua, praticada apenas no Cemitério Municipal, em que o comerciante está há 20 anos diariamente no local, enquanto no Cemitério Jardim Santa Rita o comércio ocorre apenas nos finais de semana. A aplicação de escala de turgidez e fitossanidade foi realizada no Dia das Mães nos cemitérios da sede do município, indicando a baixa qualidade das flores envasadas e cortadas, que obtiveram nota entre 5 e 6 na escala. A preocupação dos comerciantes neste caso é centrada no volume comercializado, em detrimento da qualidade do produto. As funerárias, por sua vez, ofertam este serviço de flores envasadas, coroas fúnebres e outros. $\mathrm{Na}$ sua maioria têm pré-contratos com floriculturas varejistas, em função da grande demanda, caracterizando parcerias entre funerárias e floriculturas. A aplicação da escala de turgidez e sanidade, neste caso, corresponde à nota 1 , lembrando que se trata de produtos oriundos diretamente das floriculturas varejistas.

\section{CONCLUSÕES}

O mercado varejista de flores e plantas ornamentais do município de Santa Maria caracteriza-se pelo varejo tradicional, composto por 23 empresas voltadas para produtos florais, em três segmentos propostos por este trabalho: floriculturas de arranjos, buquês e envasadas (14 unidades), floriculturas paisagistas (sete unidades) e floriculturas produtoras (duas unidades).

A origem dos produtos da floricultura varejista comercializados em Santa Maria é SP, RS e SC. A principal espécie de flor de corte comercializada é a rosa. $\mathrm{Na}$ categoria flores envasadas destacam-se a begônia e o crisântemo. O Dia das Mães é a principal data para o setor. O Dia Internacional da Mulher, Dia dos Pais, Natal, Ano Novo e datas religiosas locais são as datas comemorativas com potencial comercial.

Os estabelecimentos que apresentaram notas mais altas para os produtos quanto à turgidez e a fitossanidade foram às funerárias, as lojas agropecuárias e os supermercados.

\section{REFERÊNCIAS}

AKI, A. Bússola da comercialização para produtores de ornamentais. Holambra: Heliza Ed. Com. e Ind. Gráfica Ltda., 2002.

AKI, A. Consultoria Especializada em Marketing para flores e Plantas Ornamentais. Dados do Setor - 2010. ABAFEP - Associação Brasileira do Agronegócio de Flores e Plantas. Holambra. 2010. Disponível em <http:// www.abafep.com.br/dadosSetor.php $>$. Acesso em: 05 de junho de 2013.

AKI, A. Gestão de oportunidades no mercado de flores e plantas. Revista Brasileira de Horticultura Ornamental, Campinas, v. 6, n. 1/2, p. 15-17, 2000.

ALMEIDA, F.R.F.; AKI, A.Y. Grande crescimento no mercado das flores. Revista Agroanalysis, Rio de Janeiro, v.15, n.9, p.8-11, 1995.

ANDRADE, L. Flores, um mercado em ascensão: entrada de grandes redes de supermercados como canais de distribuição catalisa crescimento do setor, 2013. 2013. Disponível em: <http://www.souagro.com.br/flores-ummercado-em-ascensao $>$. Acesso em: 17 de junho de 2013. 
BONGERS, F.J.G. A distribuição de flores e plantas ornamentais e o sistema eletrônico integrado de comercialização. Revista Brasileira de Horticultura Ornamental, Campinas, v.8, n.1 / 2, p.49-56, 2002.

CASTRO, C.E.F. Cadeia produtiva de flores e plantas ornamentais. Revista Brasileira de Horticultura Ornamental, Campinas, v. 4, n. 1/2, p. 1-46, 1998.

CLARO, D.P.; SANTOS, A.C.; ALENCAR, E.; ANTONIALLI, L.M.; LIMA, J.B. O Complexo Agroindustrial das Flores do Brasil e suas peculiaridades. Organizações Rurais e Agroindustriais. Revista de Administração da UFLA, Lavras, v.1, n.2, 1999.

IBGE Cidades@ - INSTITUTO BRASILEIRO DE GEOGRAFIA E ESTATÍSTICA PARA AS CIDADES

BRASILEIRAS. RS - Santa Maria. 2010. Disponível em: <http://www.ibge.gov.br/cidadesat $>$. Acesso em: 02 de junho de 2013.

JUNQUEIRA, A.H.; PEETZ, M.S. Mercado interno para os produtos da floricultura brasileira: características, tendências e importância socioeconômica recente. Revista Brasileira de Horticultura Ornamental, Campinas, v.14, n.1, p.37-52, 2008.

KÄMPF, A.N. Produção comercial de plantas ornamentais. Guaíba: Agropecuária, 2000. 254p.
KÄMPF, A.N; DAUDT, R.S. Diagnóstico da floricultura no Rio Grande do Sul. Revista Ciência Rural, Santa Maria, v. 29, n. 3, p. 561-563, 1999.

PADULA, A.D.; KÄMPF, A.N.; SLONGO, L.A. Diagnóstico da cadeia produtiva de flores e plantas ornamentais do Rio Grande do Sul. Porto Alegre: SEBRAE, 2003.

SANTANA, E. Nem tudo são rosas. Revista Tecnologística. São Paulo, v.22, n.251, p.18-24, 1997.

SCHOENMAKER, K. IBRAFLOR - Release Imprensa. Instituto Brasileiro de Floricultura. 2013. Disponível em: $<$ http://www.ibraflor.com/publicacoes/vw.php?cod=213> Acesso em: 10 de fevereiro de 2013.

SEBRAE - SERVIÇO BRASILEIRO DE APOIO ÀS MICRO E PEQUENAS EMPRESAS, Manual técnico instrucional para o setor de varejo de flores e plantas ornamentais. Volume 4. Séries Manuais Técnicos Instrucionais para o Setor de Floricultura e Plantas Ornamentais - Região Norte do Brasil. 2010.

TOMBOLATO, A.F.C.; UZZO, R.P.; JUNQUEIRA, A.H.; PEETZ, M.S.; STANCATO, G.C.; ALEXANDRE, M.A.V. Bulbosas ornamentais no Brasil. Revista Brasileira de Horticultura Ornamental, Campinas, v.16, n.2, p.127138, 2010. 
